\title{
Control of Phytophthora nicotianae with Mefenoxam, Fresh Brassica Tissues, and Brassica Pellets
}

Carmen Morales-Rodríguez, Carolina Palo, Eloy Palo, and M. Carmen Rodríguez-Molina, Instituto de Investigaciónes Agrarias Finca "La Orden-Valdesequera", CICYTEX, Gobierno de Extremadura, Finca La Orden 06187 Guadajira (Badajoz), Spain

\begin{abstract}
Morales-Rodríguez, C., Palo, C., Palo, E., and Rodríguez-Molina, M. C. 2014. Control of Phytophthora nicotianae with mefenoxam, fresh Brassica tissues, and Brassica pellets. Plant Dis. 98:77-83.

Sensitivity to mefenoxam, fresh Brassicaceae tissues, and Brassica pellets was evaluated in several isolates of Phytophthora nicotianae recovered from pepper and tomato plants. The isolates of $P$. nicotianae studied were classified as sensitive to mefenoxam, showing great variability among isolates in the 50 and $90 \%$ effective concentrations $\left(\mathrm{EC}_{50}\right.$ and $\mathrm{EC}_{90}$, respectively). Sensitivity differentiated isolates from the two hosts of origin, being isolates from tomato plants more resistant to fungicide than those from pepper plants. This differentiation also occurred in the case of fresh Brassicaceae tissues assay. The most effective biofumigant in inhibiting mycelial growth of $P$. nicotianae isolates was Brassica nigra. The effectiveness of B. carinata, Sinapis

$a l b a$, and $B$. oleracea varied depending on the dose. Isolates differed in susceptibility to compounds released by the Brassica pellets and then in the $\mathrm{EC}_{50}$ and $\mathrm{EC}_{90}$. No significant difference was found between the isolates depending on the host of origin. Greenhouse tests demonstrated the effectiveness of treatments with mefenoxam and with Brassica pellets to control P. nicotianae in pepper plants. Mefenoxam application could be a solution to the disease caused by $P$. nicotianae in tomato and pepper crops in this region but its use could increase resistance in populations. Biofumigation is a promising technique which can be further developed to form part of integrated pest management strategies.
\end{abstract}

Phytophthora nicotianae Breda de Haan (= P. parasitica Dastur) is one of the most widespread and destructive soilborne plant pathogens. This oomycete is also known as a worldwide pathogen on tomato and pepper plants, causing disease in many countries (12). Soil fumigation with toxic volatile compounds is a usual practice to control this pathogen. Currently, many of the compounds used in this control, such as methyl bromide, 1,3-dichloropropene, or chloropicrin, are not included in Annex I (Directive 91/414/CEE). Since its first introduction in 1977, metalaxyl and its more recent isomer mefenoxam have been used widely and intensively to control of diseases caused by oomycetes in numerous crops, including ornamentals $(9,12)$, and it is one of the few products currently allowed in this region. Development of resistance to metalaxyl and mefenoxam has been frequently detected in several Phytophthora spp. and oomycetes $(17,27,42)$. Information on fitness of mefenoxam-resistant and -sensitive populations in $P$. nicotianae is particularly important because of its central role in population dynamics and in making antiresistance strategies (16). To detect shifts in metalaxyl sensitivity within a given Phytophthora sp., the natural range of sensitivity needs to be determined. Inhibition of mycelial growth in vitro has been used as the primary method for determining metalaxyl sensitivity of Phytophthora spp. (36).

According to the existing regulations for the cultivation of pepper for paprika in this region (DOE number 73, 2010), it is mandatory to establish a program of crop rotation, recommended not to repeat the pepper crop during consecutive years, and forbidden to repeat the pepper crop if this has been affected by Phytophthora spp., the previous year. The use of mefenoxam is authorized only as a preventive treatment in plots affected in previous years by Phytophthora spp. (P. nicotianae being the only described species in this area) and the treatment is not recommended once the dis-

Corresponding author: C. Morales-Rodríguez,

E-mail: moralescorreo@hotmail.com

Accepted for publication 15 July 2013.

http://dx.doi.org/10.1094/PDIS-04-13-0393-RE

(C) 2014 The American Phytopathological Society ease has emerged. In the case of tomato (DOE number 54, 2003), crop rotation is not mandatory; it is only recommended not to repeat a tomato crop in the same plot for more than 2 years. Fungicide treatment is mandatory in plants before transplant in the field, with the periodical application of metalaxyl in seedbeds in a preventive way recommended. During the crop, treatment with metalaxyl is authorized not only in a preventive way but also once the disease caused by $P$. nicotianae has manifested (Bulletin of the Plant Health Department of the Government of Extremadura; http://aym.juntaex.es). Additionally, the application of the mix mefenoxam + mancozeb is recommended in wet periods to prevent diseases caused by $P$. infestans and Alternaria solani or A. tenuis.

Due to the ban of products commonly used, alternative methods to control soilborne disease are needed to maintain high agricultural production in places where serious soilborne diseases are active. Moreover, the use of natural compounds is considered desirable to reduce the dependency on synthetic compounds for disease control, because natural compounds are often considered to be more environmentally friendly than synthetic compounds (15). Biofumigation refers to the suppression of soilborne pests and pathogens by biocidal compounds released by species of Brassicaceae when glucosinolates (GSLs) in their tissues are hydrolyzed by the myrosinase enzyme (35). These hydrolysis products, in particular the isothiocyanates (ITCs), are known to have broad biocidal activity, including insecticidal, nematicidal, fungicidal, antibiotic, and phytotoxic effects $(8,33)$. Biofumigation can be achieved by incorporating fresh plant material (green manure), seed meals (a byproduct of seed crushing for oil), or died plant material treated to preserve ITC activity (15).

The range in GSL profiles, the differential toxicity of the ITCs evolved to different pests of plants, and the wide range of phenological and morphological diversity of brassicas provides scope to select or breed brassicas with enhanced biofumigation potential for particular target organisms (21). Previous studies have established the toxicity of volatiles released from Brassica tissues to several fungal root pathogens $(22,24)$, and the potential of biofumigation as a component of the integrated management of soil pests and pathogens has been demonstrated in various agricultural systems (15). Previous studies reported that the species Sinapis alba L., Brassica carinnata A. Braun, B. nigra (L.). W.D.J. Koch, and B. 
oleracea L. were effective in inhibiting the mycelial growth of $P$. nicotianae (28) but the effect of the dose of biofumigant material on mycelial growth inhibition in this pathogen is unknown. Tomato and pepper for paprika are spring and summer crops in Extremadura (southwestern Spain), and it would be possible to grow these Brassicaceae species in autumn and winter and incorporate them into the soil, some time before the transplant of tomato or pepper plants, as biofumigant green manures to control the diseases caused by $P$. nicotianae on these crops. Moreover, it is interesting to study the effectiveness of Brassica pellets in control of P. nicotianae for several reasons: Brassica pellets are available as a commercial product (then the crop in the field is not necessary), stable, independent of the weather conditions during autumn and winter, and have a positive effect as soil fertilizer.

The objectives of this research were to (i) determine the sensitivity in vitro to mefenoxam of isolates of $P$. nicotianae from pepper and tomato crops in southwestern Spain, (ii) evaluate field doses of selected Brassicaceae crops used as fresh tissues for their ability to inhibit $P$. nicotianae in vitro, (iii) determinate the sensitivity in vitro of $P$. nicotianae isolates to Brassica pellets, and (iv) evaluate the effectiveness of mefenoxam and Brassica pellets for control of $P$. nicotianae in pepper in greenhouse conditions.

\section{Materials and Methods}

Culture collection and maintenance. Inhibition effect was studied in 23 isolates of $P$. nicotianae obtained from pepper and tomato plants grown in Extremadura (southwestern Spain) and showing disease symptoms (wilting and root and crown rot). Fifteen isolates (P4, P5, P10, P11, P12, P13, P15, P18, P21, P23, P26, $\mathrm{P} 28, \mathrm{P} 29, \mathrm{P} 32$, and P35) were recovered from pepper plants (32) and eight isolates (T1, T2, T3, T4, T5, T6, T7, and T8) from tomato plants (28). Isolates were grown on V8 juice agar (11) at $25^{\circ} \mathrm{C}$ for 3 to 5 days before starting the inhibition assays.

Mefenoxam sensitivity, 50 and $90 \%$ effective concentrations. Responses to the fungicide mefenoxam were determined by growing the isolates on V8 juice agar amended with Ridomil Gold SL (48\% g mefenoxam $\mathrm{ml}^{-1}$; Syngenta) suspended in sterile distilled water and added to V8 juice agar autoclaved and cooled to $50^{\circ} \mathrm{C}$. In the first test, concentrations of mefenoxam of $0.1,1,5,10,15,50$, $100,150,200,500$, and $1,000 \mu \mathrm{g} / \mathrm{ml}$ were tested, obtaining 90 to $100 \%$ growth inhibition at a mefenoxam concentration of 15 $\mathrm{mg} / \mathrm{ml}$ (data not shown). Therefore, mefenoxam concentrations of $0.062,0.125,0.25,0.5,1,2,4,8,16$, and $32 \mu \mathrm{g} / \mathrm{ml}$ were employed in this study.

According with the protocol reported by Parra and Ristaino (31), stock cultures from the isolates were grown on V8 juice agar and mycelial plugs ( $7 \mathrm{~mm}$ in diameter) were cut from the margin of actively growing colonies using a flamed cork borer. One plug was placed in the center of a 90-mm petri plate with $18 \mathrm{ml}$ of V8 juice agar previously amended with mefenoxam. Four replicate plates per treatment and nonamended control dishes were inoculated for each isolated. Plates were incubated at $25^{\circ} \mathrm{C}$ in the dark for $72 \mathrm{~h}$ to exclude the initial growth lag phase, ensuring that only linear growth rates under fungicide effect were estimated. After this time, colony diameters were measured in two perpendicular directions daily for the 3 following days. To calculate the percentage of inhibition, radial growth in the presence of fungicide was expressed as the mean percentage of the growth in the control plates.

Fresh Brassicaceae tissue sensitivity. Four different Brassicaceae species were assayed as biofumigant materials: $B$. carinata A. Braun, B. nigra (L.) W.D.J. Koch, B. oleracea L. var. botrytis, and $S$. alba L. Two biofumigant doses were tested for each species: 160 and $320 \mathrm{~g}$ (approximately 41 and $82 \mathrm{~g}$ dry weight, respectively), based on the amount of biomass that would be incorporated into the soil after cultivation of these species in field conditions (average of biomass incorporated during three years of cultivation: biofumigant species at 536.7, 737.1, 194.5, and $598.7 \mathrm{~g} / \mathrm{m}^{2}$, respectively). According to Berkenkamp keys (4), the inhibitory effect was evaluated at developmental stage 3.1 (peduncle elongating, many flowers open) in the case of B. carinata and stage 4.1 (seed in lower pods green and opaque) in the case of B. nigra and $S$. alba. B. oleracea was in the state suitable for harvesting, with the cauliflower well formed. Plants for the trials were sampled from the experimental field Finca La Orden (Extremadura, southwestern Spain), belonging to the government of Extremadura. Each biofumigant species was replicated four times in a randomized block design with plot of 5 by $5 \mathrm{~m}$. B. nigra, B. carinata, and $S$. alba were sown on 17 October 2008 and B. oleracea plants were transplanted the same day; plants were grown to 27 March 2009 and then incorporated into the soil for biofumigation before the transplant of a pepper crop. Plants were taken from the plots the day of establishment of the inhibition trial, and only the aboveground part (consisting of shoot, leaves, flowers, siliques, and seed, depending on the developmental stage) was collected. In the case of $B$. oleracea, only the leaves were collected, because this would be the aboveground material that would remain in the field after harvesting the cauliflower heads for market.

According to the method reported by Morales-Rodriguez et al. (28), plugs of V8 juice agar (4 $\mathrm{mm}$ in diameter) with actively growing mycelium of each isolate were cut and transferred to the center of petri plates $(55 \mathrm{~mm}$ in diameter) containing $7.5 \mathrm{ml}$ of $\mathrm{V} 8$ juice agar. The plants were cut into $1.5-$ to $2.0-\mathrm{cm}$ fragments and placed in a plastic tray ( 55 by 35 by $8 \mathrm{~cm}$, length by width by height, respectively) so that the plant material formed a uniform layer covering the entire base of the tray. A plastic mesh prevented direct contact of plant fragments with the plates and prevented possible contamination. Plates without lids were placed over the mesh, and trays were sealed with plastic film to prevent leakage of volatiles released from the tissues and incubated in the dark at $25^{\circ} \mathrm{C}$ for $72 \mathrm{~h}$. After that time, radial growth of the isolates was measured, taking two perpendicular diameter measurements for each of the plates. To calculate the percentage of inhibition, radial growth in the presence of biofumigant material was expressed as the mean percentage of the growth in the control plates.

Brassica pellet sensitivity, 50 and $90 \%$ effective concentrations. Trials were conducted by using Brassica pellets (BioFence; Triumph Italia SPA, Cerealetoscana Group). In the first test, doses of $0.5,1,2,4,8,16,32,64$, and $128 \mathrm{mg}$ of pellets per petri plate were tested, and 90 to $100 \%$ growth inhibition was achieved with doses between 16 and $32 \mathrm{mg}$ (data not shown). For this reason, doses of 5, 7.5, 10, 12.5, 15, 20, 40, and $60 \mathrm{mg}$ (40\% humidity) of pellets were used in the test. Stock cultures from the isolates were grown on V8 juice agar for 5 days. Mycelial plugs $(4 \mathrm{~mm}$ in diameter) were cut from the margin of actively growing colonies using a flamed cork borer. One plug was placed in the center of a 90-mm petri plate with $10 \mathrm{ml}$ of PARPH-V8 juice agar (13) to prevent possible contaminations. All plates were incubated for $24 \mathrm{~h}$ at $25^{\circ} \mathrm{C}$ and, after this time, plates were inverted, the biofumigant material was placed on the covers of plates, and the plates were immediately sealed with Parafilm and incubated inverted, in the dark at $25^{\circ} \mathrm{C}$. Radial growth of the pathogen was measured (two perpendicular diameters) at $24 \mathrm{~h}$, to exclude the initial growth lag phase, and thereafter at 3 and 6 days to evaluate whether the inhibitory effect of biofumigant was constant over time. To calculate the percentage of inhibition, radial growth in the presence of biofumigant material was expressed as the mean percentage of the growth in the control plates. Two measures were considered: growth 3 days after the pellet addition and growth between the third and the sixth day. The experiment was conducted with four replicate plates per isolate and per dose in consecutive weeks and using different samples of pellets in each repetition.

Greenhouse trials. Trials were conducted by using mefenoxam (Ridomil Gold SL) and Brassica pellets (BioFence). The treatments were (i) mefenoxam in infested soil, (ii) mefenoxam in noninfested soil, (iii) Brassica pellets in infested soil, (iv) Brassica pellets in noninfested soil, (v) nontreated soil but infested, and (vi) nontreated and noninfested soil. The trial was conducted in pots of 74 by 18 by $14 \mathrm{~cm}$ (length by width by height) with sterilized (autoclaved for $1 \mathrm{~h}$ at $120^{\circ} \mathrm{C}$ ) vermiculite/peat mixture (1:1 volume, 14 liters/pot). On the first day of the trial, the soil was inocu- 
lated with an isolate of $P$. nicotianae (P23) highly pathogenic on pepper plants (32). To produce the inoculum, the isolate was grown in 90-mm-diameter petri dishes containing $18 \mathrm{ml}$ of V8 juice-agar until the mycelium entirely colonized each plate. A suspension of propagules was prepared by blending $100 \mathrm{ml}$ of distilled water with the isolate grown on one petri dish (41). Two petri dishes were used for each pot, and the mycelial suspension was diluted in 2 liters of water so that the inoculum was uniformly distributed into the soil, with a final concentration of $200 \mathrm{CFU} /$ liter of soil. Sterile petri dishes containing only V8 juice agar were used for controls (noninfested soil). On the second day of the trial, mefenoxam and Brassica pellets were applied based on commercial recommendations (1 liter/ha and $300 \mathrm{~g} / \mathrm{m}^{2}$, respectively). The pots corresponding to Brassica pellet treatments were sealed with plastic to prevent leakage of volatiles released from the tissues and preserved in this way for 7 days. After this time, the plastic was removed, the soil was aerated, and pepper plants were transplanted. In the case of the rest of the treatments, pepper plants were transplanted the third day of the trial. Five plants of red pepper (Capsicum annum var. jaranda) at the four- to six-true-leaf stage were used per pot. Four replicates for each treatment were performed. During the trial, the pots were maintained in an automated greenhouse (photoperiod of $16 \mathrm{~h}$ of light at $28^{\circ} \mathrm{C}$ and $8 \mathrm{~h}$ of darkness at $\left.22^{\circ} \mathrm{C}\right)$.

After 6 weeks of growth, all pepper plants were harvested, washed, and rated for root and stem canker on a scale of 0 to 5 according to Larkin and Griffin (24), where $0=$ no symptoms; $1=$ brown discoloration of roots; $2=$ distinct canker lesions, covering $<50 \%$ of root circumference; $3=$ severe cankers, covering $>50 \%$ of root circumference; $4=$ cankers completely girdling stem or root and covering $>50 \%$ of total root surface; and $5=$ roots and stems completely nipped off, $100 \%$ of root surface covered with cankers, or death of plant. Fragments of roots and crown were analyzed on potato dextrose agar and also on PARP (18) to reisolate the pathogen.

Data analyses. To evaluate the effect of mefenoxam and Brassica pellet dose-inhibition regressions, 50 and $90 \%$ effective concentrations $\left(\mathrm{EC}_{50}\right.$ and $\mathrm{EC}_{90}$, respectively) and their fiducial limits were estimated by probit analysis (14) using POLO software $(25,34)$. The Mann-Whitney $W$ test was employed for pairwise comparisons of $\mathrm{EC}_{50}$, and nonparametric tests were used for this analysis because the $\mathrm{EC}_{50}$ data did not meet the assumptions of parametric techniques (40).

Data of inhibition by fresh Brassicaceae tissues were analyzed using analysis of variance (ANOVA) with three factorial treatment structure and interactions (biofumigant species, biofumigant dose, and host of origin of the isolates as fixed factors). The arcsine transformation was used to normalize data for the analysis (40). Significance was evaluated at $P<0.05$ for all tests. Mean separation was accomplished by Fisher's protected least significant difference (LSD) test. All these analyses were conducted using STATGRAPHICS PLUS software 5.1 (Statistical Graphics Corp.).

\section{Results}

Mefenoxam sensitivity, $\mathbf{E C}_{\mathbf{5 0}}$ and $\mathbf{E C}_{\mathbf{9 0}}$. The results of mycelial growth inhibition with different concentrations of mefenoxam are presented in Table 1 . In all cases, the $t$-ratio of the slope was significant $(P<0.05)$, so that a significant dose-response line was obtained. In two mefenoxam-isolate combinations, the data did not fit the probit model as indicated by the goodness-of-fit test (Table 1). On the dose-response lines of isolates from pepper, the values of the slopes were lower than those of isolates from tomato, and the same applies to the values of the point of intersection with the ordinate axis. Also, the $\mathrm{EC}_{50}$ values of isolates from pepper were lower than those of isolates from tomato. The Mann-Whitney (Wilcoxon) test of the $\mathrm{EC}_{50}$ showed that isolates from pepper and from tomato presented a significant difference $(W=120, P<0.05)$, and confirmed that isolates from tomato had an EC significantly greater than the isolates from tomato. $\mathrm{EC}_{50}$ of isolates collected from pepper plants presented values from 0.07 to $0.95 \mu \mathrm{g} / \mathrm{ml}$ with a mean of $0.34 \mu \mathrm{g} / \mathrm{ml}$, and $\mathrm{EC}_{90}$ from 0.95 to $33.21 \mu \mathrm{g} / \mathrm{ml}$ with a mean of 9.37 $\mu \mathrm{g} / \mathrm{ml}$. In the case of isolates from tomato, the means of $\mathrm{EC}_{50}$ and $\mathrm{EC}_{90}$ were 3.85 and $17.07 \mu \mathrm{g} / \mathrm{ml}$, respectively, with values from 2.32 to $6.90 \mu \mathrm{g} / \mathrm{ml}$ for $\mathrm{EC}_{50}$ and 15.11 to $67.25 \mu \mathrm{g} / \mathrm{ml}$ for $\mathrm{EC}_{90}$.

Fresh Brassicaceae tissues sensitivity. The results of a threeway ANOVA (biofumigant species, biofumigant dose, and host of origin of the isolates as fixed factors), presented in Table 2, indicated that the mycelial growth inhibition was significantly different depending on the biofumigant species $(F=76.52, P<0.05)$, the dose employed $(F=335.05, P<0.05)$, and the host of origin $(F=$ $55.14, P<0.05)$. No significant interactions were found for the interactions host-biofumigant species or host-dose and for the

Table 1. Dose-inhibition regressions, 50 and $90 \%$ effective concentration $\left(\mathrm{EC}_{50}\right.$ and $\left.\mathrm{EC}_{90}\right)$ values, and their fiducial limits on mefenoxam-amended media of 23 isolates of Phytophthora nicotianae collected from pepper and tomato ${ }^{a}$

\begin{tabular}{|c|c|c|c|c|c|c|}
\hline \multirow[b]{2}{*}{ Isolate } & \multicolumn{2}{|c|}{ Probit regression } & \multirow[b]{2}{*}{$\mathrm{EC}_{50}(\mu \mathrm{g} / \mathrm{ml})$} & \multirow[b]{2}{*}{ 95\% FL (lower-upper) } & \multirow[b]{2}{*}{$\mathrm{EC}_{90}(\mu \mathrm{g} / \mathrm{ml})$} & \multirow[b]{2}{*}{ 95\% FL (lower-upper) } \\
\hline & Slope \pm SE & Intercept & & & & \\
\hline P4 & $1.03 \pm 0.09$ & 6.05 & 0.10 & $0.07-0.13$ & 1.69 & $1.24-2.49$ \\
\hline P5 & $0.92 \pm 0.07$ & 5.79 & 0.14 & $0.10-0.19$ & 3.41 & $2.48-5.03$ \\
\hline P10 & $0.92 \pm 0.06$ & 5.36 & 0.41 & $0.28-0.56$ & 10.15 & $6.33-19.06$ \\
\hline P11 & $0.91 \pm 0.06$ & 5.73 & 0.56 & $0.11-0.21$ & 4.12 & $2.98-6.17$ \\
\hline P12 & NA & $\ldots$ & 0.91 & $\ldots$ & 20.72 & $\ldots$ \\
\hline P13 & $0.86 \pm 0.06$ & 5.46 & 0.30 & $0.22-0.38$ & 9.03 & $6.27-14.19$ \\
\hline P15 & $0.96 \pm 0.10$ & 6.00 & 0.10 & $0.03-0.16$ & 2.01 & $1.04-6.98$ \\
\hline P18 & $1.13 \pm 0.10$ & 6.30 & 0.07 & $0.04-0.11$ & 0.95 & $0.65-1.62$ \\
\hline P21 & $0.77 \pm 0.07$ & 5.17 & 0.34 & $0.25-0.44$ & 7.42 & $4.98-12.071$ \\
\hline $\mathrm{P} 23$ & $0.87 \pm 0.07$ & 5.58 & 0.21 & $0.12-0.33$ & 6.48 & $3.40-18.09$ \\
\hline P26 & $0.83 \pm 0.07$ & 5.02 & 0.95 & $0.70-1.30$ & 33.21 & $18.69-71.47$ \\
\hline $\mathrm{P} 28$ & NA & $\ldots$ & 0.45 & $\ldots$ & 18.28 & $\ldots$ \\
\hline P29 & $0.74 \pm 0.06$ & 5.38 & 0.31 & $0.18-0.47$ & 15.93 & $8.04-44.46$ \\
\hline P32 & $0.92 \pm 0.08$ & 6.08 & 0.07 & $0.03-0.11$ & 1.63 & $1.06-3.00$ \\
\hline P35 & $0.90 \pm 0.07$ & 5.62 & 0.20 & $0.13-0.29$ & 5.54 & $3.37-11.13$ \\
\hline $\mathrm{T} 1$ & $1.30 \pm 0.08$ & 3.91 & 6.92 & $5.02-9.91$ & 67.25 & $38.72-150.22$ \\
\hline $\mathrm{T} 2$ & $4.13 \pm 0.32$ & 2.72 & 3.58 & $3.20-4.01$ & 7.32 & $6.28-9.00$ \\
\hline T3 & $3.94 \pm 0.31$ & 3.02 & 3.17 & $2.89-3.49$ & 6.71 & $5.86-7.97$ \\
\hline $\mathrm{T} 4$ & $1.58 \pm 0.10$ & 4.44 & 2.32 & $1.53-3.34$ & 15.11 & $10.00-26.14$ \\
\hline T5 & $2.73 \pm 0.18$ & 3.44 & 3.71 & $3.07-4.50$ & 10.94 & $8.45-15.70$ \\
\hline T6 & $2.39 \pm 0.15$ & 3.54 & 4.08 & $3.36-4.99$ & 14.01 & $10.55-20.76$ \\
\hline $\mathrm{T} 7$ & $3.58 \pm 0.25$ & 2.95 & 3.72 & $3.38-4.11$ & 8.48 & $7.41-10.03$ \\
\hline $\mathrm{T} 8$ & $3.94 \pm 0.29$ & 3.01 & 3.21 & $2.92-3.52$ & 6.79 & $5.98-7.97$ \\
\hline
\end{tabular}

${ }^{\text {a }}$ For all isolates, probit dose-response lines were significant $(t$-ratio test, $P<0.05)$. SE $=$ standard error, FL $=$ fiducial limits, and NA $=$ goodness-of-fit test indicated that data did not fit the probit model. 
triple interaction host-biofumigant species-x dose $(F=0.21, F=$ 0.68 , and $F=0.29$, respectively; $P>0.05$ ). The isolates from pepper plants were more sensitive to the effect of the four species of brassicas with the two doses tested. In contrast, the interaction biofumigant species-dose was significant $(F=51.54, P<0.05)$. Given these results, a one-way ANOVA was performed for each biofumigants species (Fig. 1). For the species B. nigra, B. carinata, and $S$. alba, significant differences in the inhibition were found depending on the dose employed $(F=23.05, F=318.40$, and $F=$ 349.54 , respectively; $P<0.05$ ), with a dose of $320 \mathrm{~g}$ being the most effective in the inhibition. No significant difference between doses was found with $B$. oleracea treatment $(F=1.19, P>0.05)$. To evaluate the effect of biofumigant species, a one-way ANOVA was performed for each dose of biofumigant. Significant differences were found among the species of Brassicaceae with both doses (160 g: $F=103.64, P<0.05$; and $320 \mathrm{~g}: F=35.36, P<$ 0.05). Fisher's LSD tests were performed (values followed by the same letter do not differ significantly) and, with the dose of $160 \mathrm{~g}$, the most effective species was B. nigra $(36.70 \pm 4.25 \%$; a), followed by $B$. oleracea $(30.8 \pm 5.45 \%$; b), and, finally, $S$. alba $(23.4 \pm 3.25 \%$; c) and B. carinata $(21.9 \pm 3.15 \%$; c). With the dose of $320 \mathrm{~g}$, the most effective species was also $B$. nigra $(41.5 \pm$ $4.73 \%$; a), followed by $S$. alba $(38.4 \pm 3.95 \%$; b), B. carinata $(37.3$ $\pm 3.94 \%$; b), and, finally, B. oleracea $(32 \pm 3.48 \%$; c). For both doses studied, $B$. nigra was the most effective species inhibiting mycelial growth of $P$. nicotianae.

Brassica pellet sensitivity, $\mathbf{E C}_{\mathbf{5 0}}$ and $\mathbf{E C}_{\mathbf{9 0}}$. The Brassica pellets tested inhibited the mycelial growth of all $P$. nicotianae isolates. The results of mean percentage of mycelial growth inhibition after 3 and 6 days of exposure to different doses of Brassica pellets are presented in Table 3. After 3 days of exposure to Brassica pellets, the isolates assayed were shown to be highly susceptible to the effect of the biofumigant. With increasing doses of biofumigant material, growth inhibition increased until the highest concentrations, 40 and $60 \mathrm{mg}$, resulted in $100 \%$ inhibition in all the studied isolates. The effect of biofumigant pellets decreased between the third and sixth day. There was no inhibition in $70 \%$ of cases with concentrations between 5 and $20 \mathrm{mg}$. In the remaining 30\%, only in the case of isolates T1, T7, and T8 was the percentage of inhibition greater than $50 \%$ at a concentration of $20 \mathrm{mg}$. Concentrations of 40 and $60 \mathrm{mg}$ again resulted in $100 \%$ inhibition of mycelial growth. Because of this, for calculating the $\mathrm{ECs}\left(\mathrm{EC}_{50}\right.$ and $\mathrm{EC}_{90}$ ), only the data for the third day of exposure to pellet were used. Dose-inhibition regressions, $\mathrm{EC}_{50}$ and $\mathrm{EC}_{90}$ values, and their fiducial limits are presented in Table 4. In all cases, the $t$ ratio of the slope was significant $(P<0.05)$, so that a significant doseresponse line was obtained. Isolates of $P$. nicotianae differed in susceptibility to compounds released by the pellet, with $\mathrm{EC}_{50}$ values of 5.61 to $15.14 \mathrm{mg} / \mathrm{plate}$ and $\mathrm{EC}_{90}$ values of 12.71 to 33.19 $\mathrm{mg} / \mathrm{plate}$. The Mann-Whitney (Wilcoxon) test of the $\mathrm{EC}_{50}$ showed that there were not significant differences in susceptibility between isolates from pepper and from tomato $(W=41, P>0.05)$.

Greenhouse trials. Incidence of lesions and disease severity for each treatment were calculated according to Larkin and Griffin (24) for each treatment. The incidence (percentage) of plants showing distinct canker lesions (represented by disease severity ratings of 2.0 or greater) was $0 \%$ in all the treatments except mefenoxam in infested soil, with a $5 \%$ incidence, and in nontreated but infested soils, which resulted in $100 \%$ incidence. In the same way, disease severity (based on a disease severity rating scale of 0 to 5) was 0 in all the treatments except mefenoxam in infested soil, with a 0.2 severity, and in nontreated but infested soils, with a 4.5 severity. $P$. nicotianae was reisolated from roots and crowns of all the plants that showed symptoms, thus fulfilling Koch's postulates.

\section{Discussion}

According to the scale reported by Lamour and Hausbeck (23) for $P$. capsici, which has been also used for P. nicotianae (16), all the isolates of $P$. nicotianae studied were classified as sensitive to mefenoxam, because growth with mefenoxam at $100 \mu \mathrm{g} / \mathrm{ml}$ was less than $30 \%$ of the control; none of them grew up to that concentration. Because of this, lower concentrations were used for determining the ECs. The sensitivity to this fungicide has been well studied in $P$. nicotianae from tobacco plants in different parts of the world. $\mathrm{EC}_{50}$ values for mefenoxam of between 0.04 and 0.46 $\mu \mathrm{g} / \mathrm{ml}$ have been reported in South Africa (43); most of the isolates studied in Korea showed $\mathrm{EC}_{50}$ values below $1.0 \mu \mathrm{g} / \mathrm{ml}$ and only $1.7 \%$ of them were resistant, with $\mathrm{EC}_{50}$ values greater than 100 $\mu \mathrm{g} / \mathrm{ml}(19)$; in the Unites States, $\mathrm{EC}_{50}$ values between 0.01 and $0.96 \mu \mathrm{g} / \mathrm{ml}$ have been reported (10) or the mean reported by Shew (36) of $\mathrm{EC}_{50}$ about $0.4 \mu \mathrm{g} / \mathrm{ml}$. In the case of $P$. nicotianae from citrus, $\mathrm{EC}_{50}$ values between less than 0.1 to greater than $100 \mu \mathrm{g} / \mathrm{ml}$ have been found (42). All these authors found that the sensitivity of $P$. nicotianae to fungicide varied among isolates even among isolates from the same field. In the same way, isolates of $P$. nicotianae studied in this research showed great variability in the $\mathrm{EC}_{50}$ and $\mathrm{EC}_{90}$ values; for mefenoxam, the first was 0.07 to $6.92 \mu \mathrm{g} / \mathrm{ml}$ and the second was 0.95 to $67.25 \mu \mathrm{g} / \mathrm{ml}$. Sensitivity to mefenoxam clearly differentiated between isolates from the two hosts of origin, because isolates from tomato plants were more resistant to fungicide than those from pepper plants. Silvar et al. (38) suggested a possible correlation between genetic similarity and the host or the origin of the isolates of $P$. capsici. In our case, management prac-

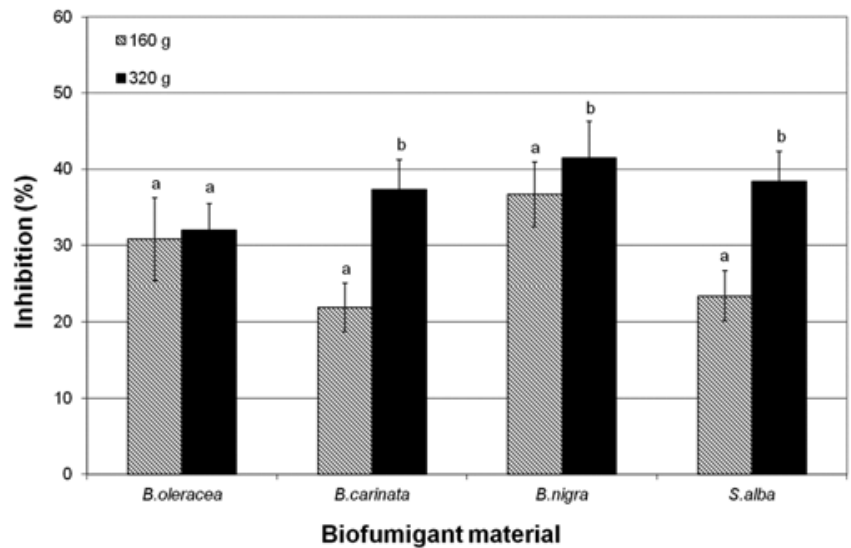

Fig. 1. Mycelial growth inhibition (percent \pm standard deviation) of 23 Phytophthora nicotianae isolates depending on the dose used for each biofumigant species. For each biofumigant species, values followed by the same letter do not differ significantly $(P<0.05)$

Table 2. Effect of the factors host of origin of the isolates (pepper or tomato), biofumigant species (Brassica nigra, B. carinata, B. oleracea, and Sinapis $a l b a)$, biofumigant dose (160 and $320 \mathrm{~g}$ ) and their interactions on the mycelial growth inhibition of Phytophthora nicotianae isolates

\begin{tabular}{|c|c|c|c|c|c|}
\hline Source & Sum of square & Degrees of freedom & Mean square & $F$ value & $P$ value $^{\text {a }}$ \\
\hline Host $(\mathrm{H})$ & 0.412 & 1 & 0.412 & 55.14 & $0.000 *$ \\
\hline Biofumigant (B) & 1.716 & 3 & 0.572 & 76.52 & $0.000 *$ \\
\hline Dose (D) & 2.505 & 1 & 2.505 & 335.05 & $0.000 *$ \\
\hline $\mathrm{H} \times \mathrm{B}$ & 0.004 & 3 & 0.001 & 0.21 & 0.889 \\
\hline $\mathrm{H} \times \mathrm{D}$ & 0.005 & 1 & 0.005 & 0.68 & 0.411 \\
\hline$B \times D$ & 1.156 & 3 & 0.385 & 51.54 & $0.000 *$ \\
\hline $\mathrm{H} \times \mathrm{B} \times \mathrm{D}$ & 0.006 & 3 & 0.002 & 0.29 & 0.829 \\
\hline
\end{tabular}

a An asterisk (*) indicates significant differences $(P<0.05)$. 
tices specific for each crop may be implicated in this differentiation because, in the pepper cropping area, the treatment with mefenoxam is less frequent and more spaced in time whereas, in the tomato cropping area, the treatment is frequent and from the seedbeds stage and, therefore, could have favored the selection of a P. nicotianae population having a higher resistance to mefenoxam.

This differentiation between isolates depending on the host of origin also occurred in the case of the fresh Brassicaceae tissues assay. The isolates from pepper plants were more sensitive to the effect of the four species of Brassica and, at both doses tested, than those from tomato, according to previous studies with these isolates (28). Because the application of biofumigants is not a common practice in either crop of origin, it is possible to speculate on the existence of cross-resistance between mefenoxam and ITCs, manifested in isolates from tomato plants. The obtained results showed that the most effective biofumigant in inhibiting mycelial growth of $P$. nicotianae isolates was $B$. nigra. Among the four biofumigants tested, $B$. nigra is the one with a higher concentration of 2-propenyl (21). The effectiveness of the other three biofumigant species varied depending on the dose. $S$. alba and $B$. carinata presented similar inhibition values. With the $160 \mathrm{~g}$ dose, B. oleracea was more effective than these two species whereas, at the $360-\mathrm{g}$ dose, $B$. oleracea was less effective than them. $B$. carinata has almost as high a concentration of aliphatic GSLs as B. nigra but, unlike this, B. nigra has aromatic GSLs, and the total number of ITCs released is lower in B. carinata. S. alba presents the highest values of total GSLs and ITCs released compared with the other three biofumigants tested because of the high concentration of aromatic GSLs but the concentrations of other GSLs (aliphatic and indole) are very low (21). In B. oleracea, the only aliphatic GSL is

Table 3. Mean percentages of mycelial growth inhibition of Phytophthora nicotianae isolates from pepper and tomato plants after 3 and 6 days of exposure to eight different doses of Brassica pellets

\begin{tabular}{|c|c|c|c|c|c|c|c|c|}
\hline \multirow[b]{2}{*}{ Isolate } & \multicolumn{8}{|c|}{ Mycelial growth inhibition $(\%)^{a}$} \\
\hline & $5 \mathrm{mg}$ & $7.5 \mathrm{mg}$ & $10 \mathrm{mg}$ & $12.5 \mathrm{mg}$ & $15 \mathrm{mg}$ & $20 \mathrm{mg}$ & $40 \mathrm{mg}$ & $60 \mathrm{mg}$ \\
\hline P4 & $29(0)$ & $32(0)$ & $45(0)$ & $57(0)$ & $87(13)$ & $97(45)$ & $100(100)$ & $100(100)$ \\
\hline P5 & $12(4)$ & $20(12)$ & $25(9)$ & $44(10)$ & $48(15)$ & $67(15)$ & $100(76)$ & $100(100)$ \\
\hline P10 & $39(0)$ & $46(0)$ & $59(0)$ & $68(0)$ & $80(0)$ & $89(18)$ & $100(100)$ & $100(100)$ \\
\hline P11 & $0(0)$ & $18(8)$ & $18(0)$ & $30(0)$ & $45(0)$ & $52(3)$ & $100(100)$ & $100(100)$ \\
\hline P12 & 17 (17) & $25(25)$ & $35(0)$ & $38(0)$ & $62(0)$ & $90(20)$ & $100(100)$ & $100(100)$ \\
\hline P13 & $18(5)$ & $38(0)$ & $57(0)$ & $58(0)$ & $71(0)$ & $95(31)$ & $100(100)$ & $100(100)$ \\
\hline P15 & $9(0)$ & $23(4)$ & $41(0)$ & $54(0)$ & $69(0)$ & $81(0)$ & $100(100)$ & $100(100)$ \\
\hline P18 & $0(0)$ & $17(5)$ & $39(0)$ & $57(0)$ & $58(0)$ & $81(22)$ & $100(100)$ & $100(100)$ \\
\hline P21 & $19(0)$ & $37(0)$ & $57(0)$ & $52(0)$ & $78(0)$ & $92(0)$ & $100(100)$ & $100(100)$ \\
\hline P23 & $19(16)$ & $26(12)$ & 47 (18) & $61(16)$ & $63(14)$ & $95(19)$ & $100(100)$ & $100(100)$ \\
\hline P26 & $46(0)$ & $66(0)$ & $79(0)$ & $65(0)$ & $92(0)$ & $100(0)$ & $100(100)$ & $100(100)$ \\
\hline P28 & $6(0)$ & $16(0)$ & $23(0)$ & $34(0)$ & $55(0)$ & $82(0)$ & $100(85)$ & $100(100)$ \\
\hline P32 & $11(0)$ & $26(0)$ & $25(0)$ & $57(0)$ & $67(0)$ & $88(31)$ & $100(100)$ & $100(100)$ \\
\hline $\mathrm{T} 1$ & $15(0)$ & $55(0)$ & $66(0)$ & $82(0)$ & $90(0)$ & $100(69)$ & $100(100)$ & $100(100)$ \\
\hline $\mathrm{T} 2$ & $5(0)$ & $8(0)$ & $38(0)$ & $40(0)$ & $61(0)$ & $97(41)$ & $100(100)$ & $100(100)$ \\
\hline $\mathrm{T} 3$ & $5(0)$ & $28(0)$ & $40(0)$ & $53(0)$ & $70(0)$ & $98(0)$ & $100(100)$ & $100(100)$ \\
\hline $\mathrm{T} 4$ & $20(0)$ & $32(0)$ & $51(0)$ & $70(0)$ & $77(0)$ & $100(37)$ & $100(100)$ & $100(100)$ \\
\hline T5 & $2(0)$ & $34(0)$ & $41(0)$ & $54(0)$ & $68(0)$ & $96(0)$ & $100(100)$ & $100(100)$ \\
\hline T6 & 27 (7) & $36(15)$ & $42(0)$ & $60(0)$ & $78(0)$ & $98(0)$ & $100(100)$ & $100(100)$ \\
\hline $\mathrm{T} 7$ & $24(12)$ & $38(0)$ & $56(0)$ & $75(0)$ & $97(0)$ & $98(60)$ & $100(100)$ & $100(100)$ \\
\hline T8 & $32(0)$ & $39(0)$ & $68(1)$ & $69(3)$ & $98(41)$ & $100(98)$ & $100(100)$ & $100(100)$ \\
\hline
\end{tabular}

${ }^{a}$ Mycelial growth in presence of biofumigant expressed as percentage of growth in control plates for doses of Brassica pellets (BioFence) employed with $40 \%$ of humidity (milligrams of pellet per $90-\mathrm{mm}$ petri plate). First number indicates mycelial growth inhibition after 3 days of exposure to Brassica pellets and number in parentheses indicates mycelial growth inhibition between 3 and 6 days of exposure to Brassica pellets.

Table 4. Dose-inhibition regressions, 50 and $90 \%$ effective concentration $\left(\mathrm{EC}_{50}\right.$ and $\left.\mathrm{EC}_{90}\right)$ values and their fiducial limits of isolates of Phytophthora nicotianae collected from pepper and tomato after exposure to Brassica pellets ${ }^{\text {a }}$

\begin{tabular}{|c|c|c|c|c|c|c|}
\hline \multirow[b]{2}{*}{ Isolate } & \multicolumn{2}{|c|}{ Probit regression } & \multirow[b]{2}{*}{$\mathrm{EC}_{50}(\mathrm{mg})$} & \multirow[b]{2}{*}{ 95\% FL (lower-upper) } & \multirow[b]{2}{*}{$\mathrm{EC}_{90}(\mathrm{mg})$} & \multirow[b]{2}{*}{ 95\% FL (lower-upper) } \\
\hline & Slope \pm SE & Intercept & & & & \\
\hline $\mathrm{P} 4$ & $5.95 \pm 0.51$ & 0.53 & 9.67 & $8.69-10.58$ & 16.39 & $14.52-19.75$ \\
\hline P5 & $3.55 \pm 0.33$ & 1.11 & 14.45 & $12.88-16.47$ & 33.19 & $26.44-48.89$ \\
\hline $\mathrm{P} 10$ & $2.84 \pm 0.23$ & 3.50 & 7.57 & $6.31-8.70$ & 21.37 & $17.803-28.12$ \\
\hline P11 & $5.94 \pm 0.66$ & -2.02 & 15.14 & $14.24-16.36$ & 24.87 & $21.88-30.17$ \\
\hline $\mathrm{P} 12$ & $4.57 \pm 0.39$ & 1.85 & 11.55 & $10.00-13.17$ & 22.05 & $18.38-30.24$ \\
\hline P13 & $3.84 \pm 0.29$ & 2.69 & 9.06 & $7.90-10.26$ & 19.52 & $16.41-25.47$ \\
\hline $\mathrm{P} 15$ & $4.06 \pm 0.28$ & 1.26 & 11.41 & $10.71-12.15$ & 23.72 & $21.37-27.04$ \\
\hline P18 & $4.79 \pm 0.34$ & 0.23 & 12.35 & $11.25-13.59$ & 22.88 & $19.78-28.44$ \\
\hline $\mathrm{P} 21$ & $3.84 \pm 0.29$ & 2.65 & 8.93 & $8.25-9.61$ & 19.24 & $17.24-22.13$ \\
\hline $\mathrm{P} 23$ & $5.19 \pm 0.50$ & 0.27 & 10.35 & $9.70-11.00$ & 18.28 & $16.55-20.99$ \\
\hline $\mathrm{P} 26$ & $3.61 \pm 0.36$ & 3.70 & 5.61 & $4.91-6.22$ & 12.71 & $11.42-14.66$ \\
\hline $\mathrm{P} 28$ & $4.93 \pm 0.38$ & 0.61 & 13.71 & $12.41-15.27$ & 24.95 & $21.18-32.58$ \\
\hline $\mathrm{P} 32$ & $4.05 \pm 0.29$ & 1.19 & 10.85 & $10.09-11.63$ & 22.47 & $20.25-25.61$ \\
\hline $\mathrm{T} 1$ & $4.93 \pm 0.37$ & 1.40 & 7.80 & $7.09-8.46$ & 14.20 & $12.83-16.28$ \\
\hline $\mathrm{T} 2$ & $5.25 \pm 0.53$ & 0.84 & 12.97 & $11.51-15.231$ & 22.76 & $18.30-36.98$ \\
\hline $\mathrm{T} 3$ & $4.37 \pm 0.36$ & 1.60 & 11.27 & $10.58-12.04$ & 22.11 & $19.64-25.90$ \\
\hline $\mathrm{T} 4$ & $3.76 \pm 0.32$ & 2.65 & 9.33 & $8.67-10.02$ & 20.47 & $18.10-24.12$ \\
\hline $\mathrm{T} 5$ & $6.19 \pm 0.62$ & -1.65 & 11.90 & $10.47-13.06$ & 19.15 & $17.13-22.89$ \\
\hline T6 & $3.99 \pm 0.46$ & 2.95 & 9.79 & $7.98-11.33$ & 20.54 & $16.75-30.81$ \\
\hline $\mathrm{T} 7$ & $4.17 \pm 0.34$ & 2.84 & 8.37 & $7.33-9.40$ & 16.99 & $14.34-22.27$ \\
\hline $\mathrm{T} 8$ & $6.95 \pm 1.06$ & -1.41 & 8.36 & $7.80-8.87$ & 12.78 & $11.57-15.18$ \\
\hline
\end{tabular}

${ }^{a}$ In all isolates, probit dose-response lines were significant $(t$ ratio test, $P<0.05)$. SE $=$ standard error and $\mathrm{FL}=$ fiducial limits. 
the 3-metilsulfinilpropil and at a very low concentration (1.4 $\mu \mathrm{mol} / \mathrm{g}$ ) compared with the concentrations of aliphatic GSLs found in the other three biofumigants tested (21). Although the four biofumigant species tested increased mycelial growth inhibition by doubling the dose, in any case the percentage of inhibition became double that achieved with the lower dose. The effectiveness of a species of Brassicaceae for biofumigation depends on factors other than the biomass dose applied. Plant tissues produce a variety of volatile inhibitors that can express additive or synergistic effects in the target organism $(3,6,7)$, and dose-response comparisons may not be adequate without an accurate measurement of concentrations of toxic gas phase involved (39). A factor as important as the production of GSLs is their ability to free ITCs. In this sense, Morra and Kirkegaard (29) reported that the main variable limiting concentrations of ITCs is not the concentration of glucosinolates but their release from plant tissues.

In B. oleracea, it is possible that GSL concentrations were too low to be significantly different between doses, especially if one considers that only $50 \%$ of these ITCs are released by hydrolysis. In contrast, $B$. nigra, $B$. carinata, and $S$. alba are species in which the GSLs that release $100 \%$ of ITCs are predominant (21).

The doses of biofumigant material tested were higher than those that would be incorporated in field conditions; nonetheless, the highest inhibition achieved, obtained with $320 \mathrm{~g}$ of $\mathrm{B}$. nigra, was less than $50 \%$. As in the previous cases, isolates of $P$. nicotianae differed in susceptibility to compounds released by the Brassica pellets, with $\mathrm{EC}_{50}$ values of 5.61 to $15.14 \mathrm{mg} /$ plate and $\mathrm{EC}_{90}$ values of 12.71 to $33.19 \mathrm{mg} /$ plate, with $100 \%$ inhibition in some cases. No significant difference was found between the isolates according to host of origin, and this may be due to the high susceptibility of both types of isolate to this biofumigant. The greatest effect of Brassica pellets in comparison with the fresh Brassicaceae tissues may be due to the higher breakdown of tissues because of the pelletization process, resulting in an increased release of ITCs. The hydrolysis of glucosinolates and, hence, the formation of ITCs in soil has been show to be dependent on the level of tissue maceration of the plant material. The highest percentage of inhibition occurs during the first 3 days after the biofumigant material addition. After this time, the isolates were not affected by the biofumigant or the inhibition effect was very low. Morra and Kirkegaard (29) reported that maximum ITC release in soil after the field incorporation of B. napus and B. juncea was measured $2 \mathrm{~h}$ after tissue incorporation and, afterward, the ITC concentrations decreased, reaching a minimum at $48 \mathrm{~h}$. They also reported that most of the ITCs were released within the first 4 days after tissue incorporation. The exact timing of this release will vary depending on soil chemical and physical characteristics, temperature, and moisture. Rapid dissipation is consistent with previously reported halflives of 20 to $60 \mathrm{~h}$ for propenyl ITC in six soils with different physical and chemical characteristics (5).

The greenhouse tests demonstrated the effectiveness of treatments with mefenoxam and with Brassica pellets to control $P$. nicotianae in pepper plants at the doses recommended by the manufacturer. However, the field treatment with mefenoxam or metalaxyl could select resistant populations that would rapidly become dominant, because they have a selective advantage over sensitive populations. The application of metalaxyl in fields of tobacco has been associated with the emergence of populations of $P$. nicotianae with low sensitivity to this fungicide in the United States, Korea, and Cuba $(10,20,30,37)$. The repeated use of metalaxyl on tobacco crops increased the selection of resistance in populations of $P$. parasitica, which became less sensitive to metalaxyl than populations that had not been exposed to treatment, with an increase of $\mathrm{EC}_{50}$ from 0.4 to $1.2 \mathrm{mg} / \mathrm{ml}$ in 3 years (37). Jaarrsveld Van et al. (44) observed that $\mathrm{EC}_{50}$ values for isolates from tobacco crops where metalaxyl was applied annually were greater than those for isolates from plantations where treatment was performed every 2 or 3 years. Moreover, when metalaxyl was used repeatedly in avocado plantation soils, it has been found to degrade rapidly due to bacterial and fungal flora soil (2) and the average lifespan of metalaxyl in soil previously treated with this fungicide was reduced (1).

The potential for biofumigant-based biocidal benefits of Brassica green manures and rotation crops are increasingly related to increased soil organic matter, improved soil structure, and erosion control (26). Moreover, the influence of green manures (and other rotation crops) in soil microbial communities may be an important factor in disease suppression. Effective rotations stimulate soil microbial biomass, activity, and diversity, and may enhance populations of microorganisms that are antagonistic to pathogens or alter microbial communities in other beneficial ways (24). Environmental risks from biofumigation are low because both glucosinolates and ITCs are short lived in soil; therefore, they do not accumulate and the risk of leaching is low. However, various degradation processes depend on the specific soil type and, under some conditions (low temperature, low water content, and in subsoils), degradation may be very slow.

Isolates of $P$. nicotianae were found to be very susceptible to treatment with mefenoxam and therefore, today, this product could be a solution to the disease caused by $P$. nicotianae in tomato and pepper crops in this region. However, the repeated use of mefenoxam could increase the resistance in populations of $P$. nicotianae. Moreover, the use of natural compounds should be considered, because our results indicated good potential for the use of Brassica spp. to control P. nicotianae. Biofumigation is a promising technique which can be further developed to form part of integrated pest management strategies to reduce reliance on synthetic pesticides, with minimal unintended impacts on the environment, and that could be used in ecological agriculture.

\section{Acknowledgments}

This research was supported by INIA project RTA 2008-00058-C03-022, Research Group GR10130 of Gobierno de Extremadura, and FEDER funds.

\section{Literature Cited}

1. Bailey, A. M., and Coffey, M. D. 1984. A sensitive bioassay for quantification of metalaxyl in soils. Phytopathology 74:667-669.

2. Bailey, A. M., and Coffey, M. D. 1985. Biodegradation of micro-organisms involved in accelerated biodegradation of metalaxyl and metalochlor in soils. Can. J. Microbiol. 32:562-569.

3. Bending, G. D., and Lincoln, S. D. 1999. Characterisation of volatile sulphur-containing compounds produced during decomposition of Brassica juncea tissues in soil. Soil Biol. Biochem. 31:695-703.

4. Berkenkamp, B. 1973. Growth-stage key for rape. Can. J. Plant Sci. 53:413 413.

5. Borek, V., Morra, M. J., Brown, P. D., and McCaffrey, J. P. 1995. Transformation of the glucosinolate-derived allelochemicals allyl isothiocyanate and allylnitrile in soil. J. Agric. Food Chem. 43:1935-1940.

6. Brown, P. D., and Morra, M. J. 1995. Glucosinolate-containing plant tissues as bioherbicides. J. Agric. Food Chem. 43:3070-3074.

7. Brown, P. D., and Morra, M. J. 1996. Hydrolysis products of glucosinolates in Brassica napus tissues as inhibitors of seed germination. Plant Soil 181:307-316.

8. Brown, P. D., and Morra, M. J. 1997. Control of soil-borne plant pests using glucosinolate-containing plants. Pages 167-231 in: Advances in Agronomy, Vol. 61. Academic Press, New York.

9. Cohen, Y., and Coffey, M. D. 1986. Systemic fungicides and the control of Oomycetes. Annu. Rev. Phytopathol. 24:311-338.

10. Csinos, A. S., and Bertrand, P. F. 1994. Distribution of Phytophthora parasitica var. nicotianae races and their sensitivity to metalaxyl in Georgia. Plant Dis. 78:471-474.

11. Erwin, D. C., Bartnicki-Garcia, S., and Tsao, P. H., eds. 1983. Phytophthora: Its Biology, Taxonomy, Ecology, and Pathology. American Phytopathological Society, St. Paul, MN.

12. Erwin, D. C., and Ribeiro, O. K. 1996. Phytophthora Diseases Worldwide. American Phytopathological Society, St. Paul, MN.

13. Fichtner, E. J., Lynch, S. C., and Rizzo, D. M. 2007. Detection, distribution, sporulation, and survival of Phytophthora ramorum in a California redwood-tanoak forest Soil. Phytopathology 97:1366-1375.

14. Finney, D. F. 1971. Probit analysis. Cambridge University Press.

15. Gimsing, A. L., and Kirkegaard, J. A. 2009. Glucosinolates and biofumigation: fate of glucosinolates and their hydrolysis products in soil. Phytochem. Rev. 8:299-310.

16. Hu, J. H., Hong, C. X., Stromberg, E. L., and Moorman, G. W. 2008 Mefenoxam sensitivity and fitness analysis of Phytophthora nicotianae isolates from nurseries in Virginia, USA. Plant Pathol. 57:728-736.

17. Hwang, J., and Benson, D. M. 2005. Identification, mefenoxam sensitivity, 
and compatibility type of Phytophthora spp. attacking floriculture crops in North Carolina. Plant Dis. 89:185-190.

18. Jeffers, S. N., and Martin, S. B. 1986. Comparison of two media selective for Phytophthora and Pythium species. Plant Dis. 70:1038-1043.

19. Kang, Y. G. 2000. In vitro sensitivity to metalaxyl of Phytophthora parasitica var. nicotianae isolates from burley tobacco in Korea. Plant Pathol. J. 16:222-226.

20. Kim, J. H., and Kang, Y. K. 1997. Screening alternative fungicides to control metalaxyl resistant Phytophthora parasitica var. nicotianae in Korea. Inf. Bull. Coresta 2:128.

21. Kirkegaard, J. A., and Sarwar, M. 1998. Biofumigation potential of brassicas-I. Variation in glucosinolate profiles of diverse field-grown brassicas. Plant Soil 201:71-89.

22. Kirkegaard, J. A., Wong, P. T. W., and Desmarchelier, J. M. 1996. In vitro suppression of fungal root pathogens of cereals by Brassica tissues. Plant Pathol. 45:593-603.

23. Lamour, K. H., and Hausbeck, M. K. 2000. Mefenoxam insensitivity and the sexual stage of Phytophthora capsici in Michigan cucurbit fields. Phytopathology 90:396-400.

24. Larkin, R. P., and Griffin, T. S. 2007. Control of soilborne potato diseases using Brassica green manures. Crop Prot. 26:1067-1077.

25. LeOra-Software. 1987. POLO-PC: A User's Guide to Probit or Logit Analysis. LeOra Software, Berkeley, CA.

26. Matthiessen, J. N., and Shackleton, M. A. 2005. Biofumigation: environmental impacts on the biological activity of diverse pure and plant-derived isothiocyanates. Pest Manage. Sci. 61:1043-1051.

27. Moorman, G. W., and Kim, S. H. 2004. Species of Pythium from greenhouses in Pennsylvania exhibit resistance to propamocarb and mefenoxam. Plant Dis. 88:630-632.

28. Morales-Rodríguez, C., Picón-Toro, J., Palo, C., Palo, E. J., García, Á., and Rodríguez-Molina, C. 2012. In vitro inhibition of mycelial growth of Phytophthora nicotianae Breda de Haan from different hosts by Brassicaceae species. Effect of the developmental stage of the biofumigant plants. Pest Manage. Sci. 68:1317-1322.

29. Morra, M. J., and Kirkegaard, J. A. 2002. Isothiocyanate release from soilincorporated Brassica tissues. Soil Biol. Biochem. 34:1683-1690.

30. Muino, B., Diaz, I., and Jaenz, A. 1990. Evidence of resistance against metalaxyl of strains of Phytophthora parasitica var. nicotianae in tobacco areas of Pinar de Rio province. Ciencia y Técnica en la Agricultura, Tabaco 13:9-67.

31. Parra, G., and Ristaino, J. B. 2001. Resistance to mefenoxam and metalaxyl among field isolates of Phytophthora capsici causing Phytophthora blight of bell pepper. Plant Dis. 85:1069-1075.

32. Rodríguez-Molina, M. C., Morales-Rodríguez, M. C., Palo, C., Palo, E. J., Verdejo, E., Duarte, M. S., and Picón-Toro, J. 2010. Short communication. Phytophthora nicotianae, the causal agent of root and crown rot (Tristeza disease) of red pepper in La Vera region (Caceres, Spain). Span. J. Agric Res. 8:770-774.

33. Rosa, E. A. S., Heaney, R. K., Fenwick, G. R., and Portas, C. A. M. 1997. Glucosinolates in Crop Plants. Pages 99-215 in: Horticultural Reviews. John Wiley \& Sons, Inc., Oxford.

34. Russell, R. N., Robertson, J. L., and Savin, N. E. 1977. Polo: a new computer program for probit analysis. . Bull. Entomol. Soc. Am. 23:209-215.

35. Sarwar, M., and Kirkegaard, J. A. 1998. Biofumigation potential of brassicas-II. Effect of environment and ontogeny on glucosinolate production and implications for screening. Plant Soil 201:91-101.

36. Shew, H. D. 1984. In vitro growth response of Phytophthora parasitica var nicotianae isolates to metalaxyl. Plant Dis. 68:764-766.

37. Shew, H. D. 1985. Response of Phytophthora parasitica var. nicotianae to metalaxyl exposure. Plant Dis. 69:559-562.

38. Silvar, C., Merino, F., and Diaz, J. 2006. Diversity of Phytophthora capsici in northwest Spain: Analysis of virulence, metalaxyl response, and molecular characterization. Plant Dis. 90:1135-1142.

39. Smolinska, U., Morra, M. J., Knudsen, G. R., and James, R. L. 2003. Isothiocyanates produced by Brassicaceae species as inhibitors of Fusarium oxysporum. Plant Dis. 87:407-412.

40. Sokal, R. R., and Rohlf, F. J. 1995. Biometry: the Principles and Practice of Statistics in Biological Research. W. H. Freeman, New York.

41. Tello, J. C., Vares, F., and Lacasa, A. 1991. Pruebas de patogenicidad. Pages 484 in: Manual de Laboratorio. Diagnóstico de Hongos, Bacterias y Nematodos Fitopatógenos. Ministerio de Agricultura, Pesca y Alimentación, Madrid.

42. Timmer, L. W., Graham, J. H., and Zitko, S. E. 1998. Metalaxyl-resistant isolates of Phytophthora nicotianae: occurrence, sensitivity, and competitive parasitic ability on citrus. Plant Dis. 82:254-261.

43. van Jaarsveld, E., Wingfield, M. J., and Drenth, A. 2002. Effect of metalaxyl resistance and cultivar resistance on control of Phytophthora nicotianae in tobacco. Plant Dis. 86:362-366.

44. van Jaarsveld, E., Wingfield, M. J., and Drenth, A. 2002. Evaluation of tobacco cultivars for resistance to races of Phytophthora nicotianae in South Africa. J. Phytopathol. 150:456-462. 